\title{
Carneiro da Cunha, Manuela e Cesarino, Pedro de Niemeyer. (orgs.). 2016. Politicas culturais e povos indígenas. São Paulo: Editora Unesp, 517 pp.
}

\author{
ANA CAROLINE AMORIM OLIVEIRA
}

O livro "Políticas Culturais e Povos Indígenas", organizado por Manuela Carneiro da Cunha e Pedro de Niemeyer Cesarino, discute acerca das políticas culturais que afetam os povos indígenas direta e indiretamente. Desde as políticas comumente debatidas, como as educacionais, até as políticas mais recentes sobre agricultura familiar, processos de patrimonialização e discussões sobre cultura, em suas várias dimensões, como o uso de objetos e substâncias tradicionais, práticas rituais, pinturas corporais, entre outros. Outro destaque da coletânea é a presença de "pesquisadores indígenas" ou "indígenas pesquisadores" que trazem reflexões coletivas a respeito de sua comunidade. O livro é composto por uma introdução e dezenove artigos, os quais estão divididos em duas partes temáticas: a primeira, "Cultura, patrimônio, conhecimento e xamanismo", com onze artigos. Já a segunda, "Escola e língua”, conta com sete trabalhos.

A introdução escrita pela organizadora dá o tom do livro. Carneiro da Cunha distingue políticas culturais para os índios e políticas culturais dos índios. $\mathrm{O}$ foco da análise é o modo como as políticas dos índios, para os índios e que se valem dos índios se entrelaçam e se conjugam para produzir efeitos. Para compreender como esse entrelaçamento se realiza, a antropóloga reitera a importância da etnografia, método característico da antropologia, nas análises sobre as diversas políticas culturais para os ameríndios. Os artigos presentes no livro possuem como característica em comum a análise de políticas culturais para os índios e a relação que se estabelece com as políticas dos índios, bem como os efeitos criativos que elas produzem enriquecendo o campo da antropologia.

$\mathrm{O}$ artigo de Geraldo Andrello e Tatiana Amaral S. Ferreira analisa as transformações da noção de cultura para os Tukano em "As transformações da cultura no Alto Rio Negro". Os autores colocam em destaque as mudanças da cultura a partir dos efeitos locais da repatriação de um conjunto de objetos rituais Tukano do Museu do Índio para o Rio Uaupés. Os adornos rituais trouxeram consigo a possibilidade de acesso à memória por meio de uma atualização dos conhecimentos, até então, entendidos como "perdidos" pelos Tukano. As pessoas e os objetos passaram a ser afetados conjuntamente exercendo agência mútua e recíproca. A cultura uukunsehé é revitalizada em uma nova objetificação do conhecimento dos antigos. A potência dos ornamentos, perigosa e produtiva, também trouxe a possibilidade de sonhar aos Tukano. 
O artigo de Laure Emperaire, intitulado "Patrimônio Agricultural e modernidade no Rio Negro (Amazonas)", discute as possibilidades de inserção de uma modernidade agrícola que possibilitasse aos povos indígenas da região do Rio Negro expressar suas escolhas e criatividades acerca de um "desenvolvimento agrícola" e que se apoiasse sobre um sistema agrícola marcado pela diversidade e processos contínuos de inovação e experimentação. A autora coloca em perspectiva duas políticas públicas conflitantes que tratam da agrobiodiversidade pautadas em premissas divergentes: agricultura (modelo único) versus agri-cultura (diversidade de repertório cultural). Emperaire compreende que somente novas políticas diferenciadas permitirão dar visibilidade à diversidade de formas de produzir e conferir-lhe autonomia de escolha diante de uma inserção de mercado ainda pautada na homogeneidade.

Continuando nessa linha de pensamento entre termos que "aparentemente" se opõem - global e local -, Edilene Coffaci de Lima, no artigo "A internacionalização do kampô (via ayahuasca): difusão global e feitos locais", trata sobre a difusão urbana e a internacionalização do kampô e os efeitos dele para os Katukina. A translocalização do uso do kampô e, consequentemente, os efeitos dessa difusão se dão tanto por meio das compreensões do kampô como "medicina"- "ayahuascarizada" e "científica"quanto a noção Katukina para o uso da "coisa" pelo potencial terapêutico para garantir boa disposição, “coragem”. Lima estabelece uma relação entre as transformações dos usos do kampô com as transformações na paisagem no entorno da terra indígena. Mesmo com as transformações, algo se mantém entre os Katukina: a atomização das relações com os não indígenas. A transformação da paisagem conjuga-se à transformação do uso do kampô.

Os autores Joana Cabral de Oliveira e Lucas Keese dos Santos, no artigo "Perguntas demais - multiplicidades de modos de conhecer em uma experiência de formação de pesquisadores Guarani-Mbya", trazem questionamentos sobre as possibilidades de diálogo entre modos de conhecer e, em particular, do ato de pesquisar dos Guarani-Mbya. O ponto central de reflexão é a pesquisa enquanto ferramenta a ser apropriada e transformada pelos agentes indígenas. O método utilizado de "perguntas-estímulos" provocou reclamações dos velhos, pois o conhecimento nativo Guarani-Mbya se constrói por hábito e ações que incidem no corpo, assim como um processo de observação e imitação. Diante dos "equívocos" provocados nessa relação interétnica, produziu- se uma nova forma de pesquisar com diferentes modos de conhecer.

Novamente na chave de discussão sobre as noções de cultura e transformação, Júlia Otero dos Santos trata das percepções e os efeitos da cultura entre os Arara de Rondônia a partir das transformações do ritual da Festa do Jacaré em "Ritual, 'cultura’ e transformação: a festa do Jacaré entre os Arara de Rondônia”. Essa festa passa por alterações ao ser inserida no mundo dos "projetos" e da participação de brancos no evento. Nesse contexto interétnico, a noção de "cultura" emerge ganhando força. Para os Arara, mesmo com as mudanças advindas com esse novo contexto, interessa-os a constituição de um espaço-tempo ritual estendido, que propicie relações não hostis e de respeito entre convidados e anfitriões e relações de predação com o Jacaré enquanto experimentação. Diante dessa paisagem, coloca-se a questão “o que é ser Arara quando se está virando branco?”

Continuando a reflexão acerca da noção de cultura no contexto de projetos, Artionka Capiberibe, no artigo "Não cutuque a cultura com vara curta: os Palikur e o projeto 'ponte entre povos", analisa 
os espaços de significação que se apresentam no encontro/desencontro de alteridades propiciados pelo contexto do projeto envolvendo índios e não índios. Tal composição questiona a distinção polar entre ritual (indígena) e espetáculo(ocidental) expondo uma proximidade maior entre essas duas formas de ação. Ao mesmo tempo, a participação dos índios significou a abertura do ganmap (pessoa palikur) ao contato com elementos do mundo xamânico que a Igreja Palikur trabalha incessantemente para se distanciar, ocasionando desdobramentos desse "encontro" de alteridades.

Trazendo uma discussão sobre conhecimento e conhecedores, Marcela Stockler Coelho de Souza, no artigo "Conhecimento Indígena e seus conhecedores: uma ciência duas vezes concreta", reflete sobre as relações sociais dos sujeitos conhecedores e a natureza relacional do conhecimento entre os Kĩsêdjê. Coelho aponta que os regimes indígenas de conhecimento não são equivalentes aos regimes baseados na propriedade. Enquanto o debate antropológico tende a centrar-se no conhecimento, o debate Kĩsêdjê tende a centrar-se nos conhecedores e nas relações que aparecem como sua causa e efeito demonstrando a necessidade da etnografia para a antropologia.

Outro artigo que reflete sobre a patrimonialização a partir da relação com bens culturais imateriais e propriedade intelectual é o de Joaquim Maná Lima, José Benedito Ferreira Kaxinawa, Marcos de Almeida Matos e Paulo Roberto Nunes Ferreira intitulado "Observações sobre o processo de patrimonialização dos Kene Huni Kuî". Os embates e equívocos entre as leis de patrimonialização de bens culturais imateriais e a de propriedade intelectual em relação aos pedidos de registro da pintura corporal kene, solicitado pelo povo Huni Kuĩ, têm como características a objetificação segundo o modelo de patrimônio e de propriedade que preside a discussão governamental. Enquanto que um dos focos do interesse indígena está em explicar os caminhos de circulação legítima das pinturas, isto é, reconhecer que tal objeto só poderia ter sido adquirido de uma mulher artesã huni kuni.

Numa perspectiva de inversão acerca do sentido da escrita pelos Maxacali enquanto pacificadora dos brancos, Marina Guimarães Vieira, em "A descoberta da cultura pelos Maxacali e seu projeto de pacificação dos brancos", analisa a escrita como possuidora de uma eficácia na relação com os não índios produzindo um "bem viver". A escrita da bíblia Maxacali tem o intuito de pacificar os não índios mostrando que os Maxacali têm língua e cultura singulares, portanto merecedores de admiração e respeito por meio da garantia de direitos.

Os direitos culturais, em particular, os territoriais e a relação com o parentesco e a organização espacial são objetos de análise de Nicole Soares-Pinto em "Sobre alguns modos de usar a cultura dos Outros”. A autora discute sobre as mudanças produzidas no campo do parentesco e na organização espacial entre os Djeoromitxi da Rondônia como consequência das políticas de direitos culturais. Soares-Pinto destaca em sua reflexão a dimensão concreta dos suportes (pessoas) por meio dos quais se operam a criatividade e as transformações indígenas na chave da "convivência". Ao mesmo tempo, produção de conhecimento e substância positiva e incorporada de conhecimento. A preocupação não se refere em assegurar uma cultura, mas sim assegurar o modo como os indígenas podem "usar a sua cultura e a dos outros".

Refletindo sobre conhecimento entre culturas, ou entre ontologias distintas, Pedro de Niemeyer Cesarino, no artigo "Xamanismo e novas circulações de conhecimento na Amazônia Indígena”, analisa 
os processos de transformação de ontologias ameríndias dos Marubo da Amazônia Ocidental a partir das situações de intercâmbio e/ou interlocução entre povos indígenas e pesquisadores não indígenas. Cesarino identificou uma recategorização de papéis e validações do conhecimento que tem gerado fossos internos às próprias aldeias. Conflitos geracionais e de expectativa de vida tem problematizado as dinâmicas de transmissão de conhecimento demonstrando a necessidade de etnografias mais minuciosas.

Clarice Cohn, em "A cultura nas escolas indígenas", examina a demanda indígena por escola e as possibilidades de escolarização e os impactos nos regimes de conhecimento ameríndios. Ela enfatiza a etnografia como a principal ferramenta para enfrentar analiticamente essas questões. Dois desafios são encontrados: um analítico, no qual os antropólogos têm que aprender a fazer sentido os múltiplos sentidos que ganha a escola nas aldeias, e, um indígena, porque esta política cultural é, ao mesmo tempo, uma conquista e um risco de banalização de suas culturas.

A educação escolar indigenista a partir do olhar indígena está presente no artigo "Reflexões e experiências de um estudante-liderança: sobre algumas políticas educacionais indígenas no Alto Rio Negro”. Maximiliano Menezes e Raphael Rodrigues trazem a trajetória escolar do povo Tukano, do clã Inapé-Porã, por meio das políticas educacionais presentes naquela região. A relação entre a trajetória escolar e a atuação política do autor foi sendo relembrada e marcada pelas produções intelectuais do movimento indígena. Menezes compreende que a interculturalidade entre as diferentes etnias do Rio Negro se torna necessária para poder falar em nome desses povos nos espaços de representação política, tendo como objetivo defender os direitos dessas populações para além dos problemas internos.

Uma reflexão sobre as línguas indígenas e sua patrimonialização é analisada por José R. Bessa Freire em "A demarcação das línguas indígenas no Brasil”. O artigo lança luz sobre as políticas linguísticas e sua interferência nos destinos das línguas faladas no Brasil. A criação de instrumentos de salvaguarda do patrimônio imaterial permitiu que se conhecesse melhor a situação das línguas indígenas e seus falantes. Entretanto, a memória é um caminho necessário a se percorrer em virtude do apagamento das línguas e suas lembranças.

A mistura entre línguas indígenas e não indígenas é objeto de análise em "Kagaiha akisü etĩbepügü - a chegada da língua dos brancos”, de Mutuá Mehinaku. O autor analisa a mistura entre as variantes da língua karib do Alto Xingu e a língua dos brancos, o português. Após o encontro com os kagaiha (brancos) vieram mudanças nos comportamentos, pensamentos e modo de viver dos xinguanos. $\mathrm{O}$ tetsualü, língua da nova geração, ganha um outro sentido e valor, pois o português é um ponto de comunicação entre os distintos povos. O embate geracional entre jovens e hgiholo (antigos) provocam uma exclusão destes nesse novo tipo de comunicação e uma inversão, pois os jovens são os agentes das novas tecnologias dos brancos, cabendo aos velhos a reponsabilidade de cuidar das tradições. Mehinaku busca, entretanto, uma "igualdade" entre as gerações.

Numa perspectiva contra intuitiva acerca da escrita e sua necessidade para os povos indígenas, o artigo "De 'povos ágrafos' a 'cidadãos analfabetos': as concepções teóricas subjacentes às propostas educacionais para os povos indígenas no Brasil”, de Maria Elisa Ladeira, caracteriza o paradoxo imposto pela escola entre a reificação da permanência de uma tradição imemorial e a assimilação passiva 
de novos saberes. A autora propõe como saída pensar a partir das estratégias políticas e linguísticas desenvolvidas pelos índios, nas quais o "dilema da escrita" posto por nós se refaz pelo uso e pelo sentido que dão a ela.

Em “A formação de professores indígenas na UFMG e os dilemas das 'culturas' entre os Xakriabá e os Pataxó", Ana Maria R. Gomes e Shirley Aparecida de Miranda abordam os aspectos do contexto da Formação Intercultural de Educadores Indígenas-Fiei e as relações com os Xakriabá e os Pataxó. Como desdobramento do curso, reforçou-se a complementariedade entre a formação de professores e as políticas culturais, provocando a pensá-las de forma mais atenta e estruturada. Os estudantes inauguraram novos cenários internos e externos em suas respectivas comunidades, fazendo com que a universidade e o próprio curso fossem chamados a integrar esses horizontes mais amplos.

Outra experiência de ensino superior para os índios é aprofundada por Augusto Ventura dos Santos e Luiz Henrique Eloy Amado Terena, que realizam um balanço acerca do ensino superior observando os efeitos dessa modalidade de política cultural para os índios Terena no artigo "Os Terena e o ensino superior para indígenas no Mato Grosso do Sul”. Destacam a decisão política do povo Terena em entrar na universidade e a importância dos índios universitários na luta pela retomada das terras indígenas. Ao mesmo tempo, há um despertar da juventude para a luta de suas lideranças. Tal experiência de frequentar um curso superior pode ser comparada com outras tantas experiências de deslocamentos que diversos Terena fizeram no passado e continuam a fazê-lo.

O último artigo da coletânea perfaz os questionamentos trazidos ao longo dos textos. "A escola como problema: algumas posições”, de Dominique Tilkin Gallois, trata de alguns pontos a respeito dos efeitos e dos desafios epistemológicos que se sobressaem da consolidação de programas de formação indígena. Gallois identifica como lição importante o fato de que os efeitos da apropriação escolar da categoria cultura sobre os modos diferenciados de vivenciá-la não parece tão dramática aos índios. A autonomia para os índios é a arte criativa de se apropriar de armas oferecidas pelos brancos. A proposta da autora seria radicalizar a diferença entendendo que as políticas não estão pautadas pela diversidade de modos de saber ou formas adequadas de articular conhecimentos.

Radicalizar a diferença pela via etnográfica é a tônica dos textos dessa coletânea e sua grande contribuição.

Ana Caroline Amorim Oliveira é mestre em Antropologia pela Universidade Federal do Pernambuco, doutoranda em Antropologia Social pela Universidade de São Paulo e professora adjunta de Sociologia na Universidade Federal do Maranhão.

RECEBIDO: $30 / 03 / 2018$

APROVADO: $30 / 09 / 2018$ 